\title{
Starting small: Building preschool teacher knowledge that supports early literacy development
}

\author{
Anne E. Cunningham · Jamie Zibulsky • \\ Mia D. Callahan
}

Published online: 31 January 2009

(C) The Author(s) 2009. This article is published with open access at Springerlink.com

\begin{abstract}
A growing body of research is emerging that investigates the teacher knowledge base essential for supporting reading and writing development at the elementary school level. However, even though increasing recognition is given to the pivotal role that preschool teachers play in cultivating children's early literacy development, considerably fewer studies have examined the knowledge base of these early childhood educators. This paper will discuss the existing research literature and then examine a recent study that investigated the knowledge constructs of 20 preschool teachers. Findings indicate that preschool teachers lack the disciplinary knowledge required to promote early literacy and, in fact, tend to overestimate what they know, creating a potential obstacle for seeking additional knowledge. Recommendations for strengthening professional development programs and developing more robust measures of preschool teacher knowledge are proposed.
\end{abstract}

Keywords Early literacy development

The road to literacy begins long before a child enters school, long before pencils, paper, and textbooks come into play. It begins at birth when the sounds of language are first perceived, and this journey continues throughout the preschool years, enriched by stories heard, rhymes rehearsed, and songs sung. Along with this explosion of oral language development comes an introduction to the world of written language through books, labels, and signs. The preschool years are filled

\footnotetext{
A. E. Cunningham $(\bowtie)$

Graduate School of Education, University of California, Berkeley,

4511 Tolman Hall \#1670, Berkeley, CA 94720-1670, USA

e-mail: acunning@berkeley.edu

J. Zibulsky · M. D. Callahan

University of California, Berkeley, CA, USA
} 
with rich possibilities for language development—-the foundation for continued literacy learning.

Unfortunately, not all children are provided the same opportunities for literacy development during these early years. The physical and emotional well-being of families, as well as their ability to invest in material resources related to child development, can have an impact on the quality and frequency of language-building interactions within the home (Clingenpeel \& Pianta, 2007; Duncan \& Brooks-Gunn, 1997; Hart \& Risley, 1992; Sénéchal \& LeFevre, 2002). Similarly, there are community-level disparities in accessing a range of formal and informal literacy experiences, such as the size and quality of local libraries and the amount of environmental print children see in their neighborhoods (Constantino, 2005; Duke, 2000; Neuman \& Celano, 2001). As a consequence, by the time these children enter school, a well-documented achievement gap in the domain of language and literacy exists (Princiotta, Flanagan, \& Germino Hausken, 2006; Raver \& Zigler, 2004).

Whether children come from impoverished or enriched language environments, their preschool teachers are in a unique position to provide opportunities to build the fundamental skills and knowledge they will need for the transition into the first years of formal schooling - the years when reading and writing will be among their most significant core achievements. Simply put, preschool teachers have the potential to make an invaluable contribution to the literacy development of children. For this reason, teacher educators and reading researchers have a responsibility to ensure that these individuals have the training and willingness to undertake this task.

With increasing frequency, policy discussions of children's literacy outcomes focus on issues of teacher preparation and professional knowledge, and the role these two factors play in academic achievement. At the same time, recent federal accountability initiatives demand increasing school readiness and include stringent accountability standards. Among communities of educational researchers and practitioners, there is growing recognition that adequate professional development opportunities for building teacher knowledge in the domain of literacy are critical to the academic success of children. However, crafting such training programs can be challenging because the knowledge base needed to support the development of emergent literacy skills and the teaching of reading and writing is extensive, complex, and often underestimated. Moreover, conversations about building teacher knowledge through preservice programs and professional development have tended to concentrate on the needs of elementary school teachers and students, rather than the needs of preschool teachers and their younger learners.

Despite a growing awareness of the relationship between early literacy learning and later academic success, limited attention has been directed toward studying the knowledge base of early childhood educators and its effect on the performance of their students. This lack of attention can be attributed, in part, to the underlying complexity of the task. It is daunting to determine what teachers need to know, under what circumstances, and how they need to know it to be masterful, adaptive, and responsive in the preschool classroom. The research literature on this topic is sparse even for primary grade teachers. Nonetheless, the research community must begin to investigate these complex questions by examining precisely what teachers need to know and how much of this knowledge they already possess. 
Accomplishing this requires narrowing the focus of empirical and theoretical questions by conclusively determining the content knowledge needed to assist students in developing language and literacy skills. Answering this fundamental question will lay the groundwork to focus on the application of such knowledge in future studies. Limiting the focus in this way may be frustrating to policymakers and practitioners who urgently want answers to the broader questions regarding not just what content knowledge teachers need to acquire, but how they must apply this knowledge to boost student achievement. It is important, however, to recognize that complete answers to these questions will not be available until the more foundational questions regarding teacher content knowledge have been answered.

This paper will concentrate on examining the skill of word recognition, an important aspect of the content knowledge that preschool teachers must have to effectively support early literacy. By framing the inquiry this way, it becomes possible to shed light on an important, albeit single, piece of the preschool teacher knowledge puzzle. Narrowing the research to one area of expertise in no way implies that word recognition is the only important component of skilled reading. However, we do assert that word recognition is "the access card to reading" (Juel, 2006 , p. 416). Thus, focusing on word recognition as part of a larger collection of knowledge factors is justified, because while efficient word recognition does not guarantee improved comprehension, limited comprehension is inevitable without it.

This paper includes a brief history of the study of teacher knowledge in the domain of reading. The overview is followed by the assertion that it is critical to include preschool teachers and their knowledge in this field of study, specifically to determine the knowledge needed to support the future development of word recognition skills in young children. Finally, the effectiveness of a recent preschool teacher study group (TSG) model will be examined, focusing on evaluating the ability of teachers to accurately assess their own knowledge. The discussion of this TSG model leads to a recommendation for more individualized intervention efforts to support the growth of specific content knowledge.

More than 30 years ago, educational psychologist Nathaniel Gage stated, "the importance of teacher education is commensurate with the importance of teaching" (1978, p. 42). Because preschool teachers have such a tremendous opportunity to promote children's literacy development, it is imperative that the teacher education field reflect upon and reassess standards of professional development to ensure that preschool teachers are able to capitalize on that opportunity. The first step in doing so is delineating exactly what it is that preschool teachers need to know.

\section{A brief review of the study of teacher knowledge in the literacy domain}

Over the years, there have been concerted inquiries into the knowledge base necessary for instruction in disciplines such as science and math. Surprisingly, there has not been the same level of study directed towards the field of literacy instruction. One likely reason is that literacy is not considered a discipline in the same sense that math and science are; it does not exist as a well-specified sphere of knowledge agreed upon by scholars (Phelps \& Schilling, 2004). Thus, without a clear consensus regarding the 
content of literacy, it has been difficult to design studies that can effectively explore the links between teacher education, teacher content knowledge, improved school practice, and student learning. Snow, Griffin, and Burns (2005) suggested another reason that the knowledge base for literacy instruction has been scant in teacher education research. Because it is crowded with technical elements such as phonology, morphology, orthography, syntax, semantics, pragmatics, and etymology, they believe that some may consider reading acquisition too complex and unwieldy to study. Regardless of these obstacles, a recent focus on the role of teacher preparation in children's literacy outcomes has prompted an earnest commitment to tackle the following question: What is it that teachers need to know to effectively support the literacy development of their students within the area of reading?

Common perception, both within the teaching community and outside of it, is that being a skilled reader is a sufficient condition for being a skilled reading teacher. Yet it cannot be assumed that simply because an individual is literate, he or she has the explicit awareness of the structures of spoken and written language needed for effective reading instruction. Recent studies confirm that a high level of literacy does not automatically provide the knowledge required for effective reading instruction (Bos, Mather, Narr, \& Babur, 1999; McCutchen, Abbott et al., 2002a; Scarborough, Ehri, Olson, \& Fowler, 1998). The vast majority of teachers became skilled readers far too long ago to understand the intricate process of reading development through simple introspection. Fluent readers consciously attend to the meaning of the text, not to the code translation process. When confronted with a group of beginning readers, the awareness of subtleties of word and text structure needed to guide students through the stages of reading development are, ironically, lost in the teacher's own automaticity.

\section{Essential knowledge components for the teaching of reading}

Although this paper conceptualizes literacy on a developmental continuum beginning in early childhood, the traditional view places the entry point of literacy at the start of formal education, with a clear demarcation between pre-reading and reading. Thus, much of the focus of teacher education has been centered on this "beginning point"-kindergarten, and the early elementary grades where reading instruction takes center stage. What has been determined from research about the knowledge to support the teaching of reading in elementary school will be reviewed here, and then used as a springboard for theorizing about the knowledge needed to support the growth of literacy in preschools.

Eventhough researchers do not agree about the details regarding what literacy teachers at each level should know to be effective, mounting evidence makes it increasingly possible to hypothesize about which components of knowledge are most useful to practitioners. A growing consensus of educators maintains that elementary school teachers of reading must understand the theoretical and empirical underpinnings of reading development (Brady \& Moats, 1997; Moats, 1994, 1999; Snow et al., 2005; Spear-Swerling \& Sternberg, 2001; Wong-Fillmore \& Snow, 2002). Elementary school teachers need to understand that early oral language development is the main precursor of reading development, and that it unfolds with 
a steady growth of vocabulary, a deepening of syntactical awareness, an evermaturing grasp of pragmatics, and an evolving ability to hear, blend, segment, and manipulate phonemes in words and sentences. Teachers need to recognize the vital role of word recognition skills in early reading acquisition and development-how phonological awareness and the alphabetic principle are at the very foundation of learning to decode accurately and, later, how phonologic, orthographic, syntactic, and semantic knowledge lead to automatic and fluent reading which, in turn, leads to making meaning from text. However, merely recognizing the critical role that language, text structure, and vocabulary development play in both word recognition and comprehension is not enough. Teachers need the associated content knowledge to support children as they develop reading skills.

Content knowledge, also identified as disciplinary knowledge, is the most basic form of knowledge teachers are expected to possess. In the domain of reading instruction, and more specifically the realm of word recognition, such content is largely language-based because orthography is merely a written representation of oral language. For this reason, Snow et al. (2005) suggest that reading teachers need a working knowledge of the phonological system of English, including the ability to articulate, identify, count, and manipulate phonemes; an understanding that sounds and letters are separate entities; and an understanding of the importance of secure and accurate phonological representations for words in print. Children's misconceptions about phonemes in spoken words often have to be corrected with assistance from adults who understand the correspondences between phonemes in speech and in written form (Brady \& Moats, 1997). Professional development that targets improvement of teacher knowledge in this area of the English language system can greatly increase the number of adults who are able to constructively respond to children's errors at the phoneme level. Teachers cannot develop the facility to respond to common errors in phonological awareness tasks until they have first acquired basic content knowledge in this domain. Thus, teacher professional development that cultivates detailed knowledge of the English speech sound system and its production can help teachers provide effective instruction in important elements of beginning reading, specifically word recognition.

In addition to the importance of content knowledge of phonology, content knowledge of the structure of the English orthography and its relationship to sounds and meaning is also important. In order to offer systematic, well-sequenced phonics instruction, reading teachers must have knowledge of the grapheme/phoneme conventions in English. Particularly because the English orthography has more than its share of inconsistent sound/symbol correspondences, the writing system is most appropriately taught through systematic and explicit instruction, which has been shown to be valuable for most students and critical for those who do not perceive patterns intuitively (Adams, 1990; Blachman et al., 2004; Cunningham, 1990; Foorman \& Torgesen, 2001; National Reading Panel, 2000; Oudeans, 2003; Rayner, Foorman, Perfetti, Pesetsky, \& Seidenberg, 2001). Emphasis on more sophisticated linguistic structures, such as the recognition of morphemes (the smallest meaningful units in words), is also useful because it provides teachers and students the keys to understanding the meanings of thousands of words. When a student incorrectly decodes, pronounces, or defines a word, knowledge of each of these linguistic 
structures is needed in order for a teacher to provide the appropriate feedback for the type of error made. It is only with this knowledge that teachers can interpret student errors in reading and writing, assess student progress, give appropriate feedback, and design instruction with both accuracy and confidence.

In summary, it is theorized that elementary school teachers must possess a wide range of content knowledge in order to effectively scaffold students' reading development. Increasingly, preschool teachers are also expected to explicitly and systematically provide instruction that scaffolds students in developing the early phonological skills necessary for efficient word recognition. Additionally, although researchers have successfully catalogued the competencies that elementary school teachers must acquire, creating professional development programs that effectively build such skills and then help teachers apply them are tasks that the field has only recently begun to address.

\section{What studies demonstrate about teacher knowledge of reading instruction}

For decades, researchers have studied the knowledge base of teachers across the academic disciplines (e.g., Clark \& Peterson, 1986; Lampert, 1988; Thompson, 1992; Wilson \& Wineburg, 1988) and empirically found that teachers differ greatly in their disciplinary content knowledge, and that these differences have an important effect on classroom practice (e.g., Grossman, Wilson, \& Shulman, 1989; Hill, Rowan, \& Ball, 2005; Wilson, Shulman, \& Richert, 1987). Studies in the area of literacy content knowledge, however, are still in the early stages. There is relatively little empirical data on the disciplinary knowledge elementary teachers possess in reading instruction, and even less regarding the appropriate knowledge base for preschool teachers. In recent years, however, a number of investigators have begun to examine the teacher knowledge base in this critical domain.

One of the earliest studies investigating teacher disciplinary knowledge in early reading surveyed regular and special education elementary teachers' perceptions of their own professional education (Lyon, Vaassen, \& Toomey, 1989). When asked general questions about their preparation, teachers reported feeling generally wellprepared to meet the diverse needs of student populations, explaining that they had earned high grades in the education courses they took. However, more specific survey questions revealed that the training programs they attended did not provide effective, explicit, and contextualized instruction didactically or within practicum settings. The lack of feedback regarding their capacity to differentiate instruction effectively, as well as insufficient supervision, may have contributed to teachers' false perceptions of adequate training. In this seminal paper, the authors noted that the teaching of reading should be characterized as "a job for an expert" that requires a significant level of content knowledge and procedural expertise. For this reason, Lyon et al. (1989) criticized teacher education programs that did not provide the requisite intensive theoretical and practical training. Similarly, Nolan, McCutchen, and Berninger (1990) examined teacher education programs and found a general insufficiency of teacher training in reading development and disciplinary knowledge. They asserted that teachers could not possibly be prepared to meet the diverse needs of students on the basis of the minimal requirements in teacher education. 
Delving more deeply into the area of teacher knowledge of reading and language, Moats (1994) conducted an exploratory study of literacy content knowledge by administering a survey assessing 52 graduate students' knowledge of spoken and written language structures. All of the candidates were licensed, practicing elementary school teachers with 2-20 years of classroom experience. The results of a pretest indicated unexpected difficulty with very basic items, such as consonant blends, consonant digraphs, inflectional and derivational morphemes, and positionbased spelling patterns such as the use of the spelling - ck. Notably, no correlation was found between teacher knowledge and factors associated with level of expertise, such as teaching experience or type of license held (i.e., regular or special education). Both of Moats' findings regarding the inadequate disciplinary knowledge of elementary school teachers and the lack of association between teacher preparation and knowledge spurred additional work in this field.

Recent research continues to suggest that teachers need support to acquire the disciplinary knowledge required to assist children, even in the earliest stages of literacy acquisition. For example, at the elementary school level, Cunningham, Perry, Stanovich, and Stanovich (2004) found that a high percentage of first grade teachers serving low-income communities had not mastered the knowledge base necessary for beginning reading instruction. Only two-thirds of the elementary school teachers surveyed were able to correctly identify the number of phonemes in the word sun, which was the simplest item on the administered phoneme awareness task. Furthermore, McCutchen, Harry et al. (2002) observed that across grades K-2, teachers' reading-related content knowledge was related to the instructional practices they used to identify sounds and letter/sound relationships. Finally, in a study examining in-service teachers' perceptions of their ability, Bos, Mather, Dickson, Podhajski, \& Chard (2001) reported that teachers felt largely unprepared to teach early reading skills. These studies reiterate the need to strengthen teachers' disciplinary knowledge of spoken and written language structures.

This call to increase teacher knowledge is bolstered by a growing body of research that has revealed significant links between teacher knowledge and practice, and most importantly, student reading achievement (Foorman \& Moats, 2004; McCutchen, Abbott et al., 2002; Spear-Swerling \& Brucker, 2004). The results of these studies demonstrate that educators who have knowledge of phonological awareness and the alphabetic principle, and understand how to apply such knowledge in classrooms, can positively affect student outcomes (Bos et al., 1999; McCutchen \& Berninger, 1999; O'Connor, 1999). For example, McCutchen, Abbott et al. (2002) found that teachers' disciplinary knowledge of phonics at the start of the school year was significantly related to their use of instructional practices that explicitly directed their students' focus to the sounds in language and symbol/sound correspondences. Moreover, they found that teachers who began to understand the developmental process of phonological awareness through professional development utilized different instructional strategies than those teachers who did not have a deep understanding of how aspects of phonological awareness are acquired. Perhaps most importantly, they found that deepening kindergarten teachers' knowledge of phonology was directly related to improvements in students' reading achievement. Notably, McCutchen herself has been able to replicate this pattern of 
results with older elementary school children, as detailed in McCutchen, Green, and Abbott's (in press) article in this Special Issue.

Despite the positive results of some studies in linking teacher knowledge and practice, other research findings have not documented such a relationship. For instance, McCutchen, Harry et al. (2002) did not find a significantly positive correlation between teachers' phonological knowledge and students' reading during the first and second grades. Cirino, Pollard-Durodola, Foorman, Carlson, and Francis (2007) found that teacher content knowledge was consistently unrelated to bilingual kindergarteners' literacy and language outcomes, such as letter naming, phonological awareness, and oral language. Even considering the contradictory data, there is nonetheless strong theoretical justification and growing evidence to suggest that in the early elementary grades, teachers' acquisition of content knowledge can not only lead to changes in teacher practice and beliefs but also to student progress in reading ability. The conflicting findings in the literature, however, may demonstrate that the field is still struggling to create measures of content knowledge that capture those knowledge constructs that are related to student achievement.

The associations between teacher knowledge, teacher practice, and student success have yet to be explored in the early childhood community. As the educational system becomes progressively more uniform and rigorous, early childhood educators are increasingly called upon to support the development of skills that were previously the sole purview of elementary school teachers. Recent research demonstrating the strong linkage between preschool children's early language and literacy skills and their later achievement warrants such a stance (Dickinson \& McCabe, 2001; Sénéchal \& LeFevre, 2002). Thus, it stands to reason that the body of research on teacher knowledge in these domains must be broadened to include studies of preschool teachers and their students.

\section{How and why to include preschool teachers in teacher knowledge studies}

As described earlier, the achievement gap in the domain of language and literacy can be documented well before children start kindergarten (Princiotta et al., 2006; Raver \& Zigler, 2004). Given that this considerable achievement gap exists even as children begin their formal education, early childhood educators are increasingly required to explicitly teach pre-academic skills in preschool classrooms. It has been demonstrated that reading success throughout elementary and middle school is significantly associated with emergent language and literacy skills (Dickinson \& McCabe, 2001; Sénéchal \& LeFevre, 2002). Considering that we have long known that first grade reading achievement is a reliable predictor of eleventh grade reading achievement (e.g., Cunningham \& Stanovich, 1997), it is only logical that researchers continue to explore earlier stages of reading development and uncover the factors that lead to first grade reading achievement.

It is clear that with appropriate supports and experiences during the early childhood years, children are more likely to be able to utilize the educational opportunities offered upon entering school. All children are not, however, receiving instruction and experiences that lay the foundation for learning to read before entering kindergarten. 
In 1999, the National Research Council argued that "central to achieving the goal of primary prevention of reading difficulties is the preschool teacher's knowledge base and experience, as well as the support provided to the teacher" (p. 58).

Increasing the knowledge base of preschool teachers

There is a concerted national effort underway to help preschool teachers develop a solid, working knowledge of the research base in early language and literacy skills in general, and awareness of the structure of the English language more specifically. In a joint position paper, the National Association for the Education of Young Children and National Head Start (Dickinson, 2002) emphasized the importance of teaching young children emergent literacy skills in preschool. Those emergent literacy skills include phonological awareness, phonics skills, and oral language skills-three significant predictors of later reading success (Greene, 1998; Lyon, 1998; Sénéchal \& LeFevre, 2002; Stanovich, 1986). The importance of these skills has become widely recognized at federal, state, and local levels, although attempts to incorporate them into teacher preparation programs, professional development programs, curricula, and homeliteracy interventions have been executed with varying degrees of success (Dickinson \& Brady, 2006; Roskos, Rosemary, \& Varner, 2006). In recent years, the focus of Head Start has shifted to include more direct instruction in pre-academic skills and to systematically collect assessment data that can inform the success of such efforts (U.S. Department of Health and Human Services, 2003). Many states specifically detail the emergent literacy skills that are prerequisite qualifications for kindergarten readiness in their preschool learning standards (e.g., California Department of Education, 2008). Nationwide programs such as Every Child Ready to Read @ Your Library focus on identifying sites that parents of young children are likely to visit, including doctors' offices and libraries, and then utilizing those sites to provide training and resources that support literacy acquisition skills. As a result, pediatricians, librarians, and parents are becoming increasingly educated about the type of activities that foster literacy development (Arnold, 2005; Needlman, Toker, Dreyer, Klass, \& Mendelsohn, 2005).

In spite of the strong evidence pointing to the importance of early literacy development, recent research in large, high-poverty, urban areas has suggested that preschool teachers may not have substantive knowledge of how to effectively teach language and literacy to young children (Cunningham \& Davidson, 2005; Davidson \& Cunningham, 2005; Schmidt, 2008). The fact that early childhood educators do not generally possess such knowledge can be attributed, in part, to the wide range of programs that serve children prior to their entry into the formal education system, and to the varied levels of preparation required of educators who work in these programs (Ackerman, 2004). Some children do not enroll in any sort of out-of-home program or care until starting a school program, while others attend state prekindergarten programs, Head Start centers, private preschools, or center- or familybased childcare. The level of education that employees at these disparate sites possess is as varied as the quality of the programs themselves, with some educators holding a high school diploma or GED and little formal training in child or literacy development, and others holding a graduate degree in a related field (Burchinal, Hyson, \& Zaslow, 2008; Lash, McMullen, \& Alat, 2003). 
Another explanatory factor for the lack of substantive content knowledge among preschool teachers can be gleaned by examining past research (Bos et al., 2001; Moats, 1994, 1995) as well as current findings detailed in articles in this Special Issue. The fact that elementary school teachers have difficulty teaching phonological awareness and phonics skills effectively portends even greater difficulty for preschool teachers, as educational requirements for preschool teachers are considerably less stringent, and the expectation that such teaching will occur in preschool settings is not as pervasive and longstanding. In the past 25 years, early childhood education programs have, for better or for worse, increased their focus on preacademic skills, rather than concentrating primarily on providing opportunities for play and socioemotional development (see Raver \& Zigler, 2004, for a review of the negative implications of this shift). However, while research and policy indicate the need for developmentally appropriate instruction in language and literacy, few teacher education programs-even today-prepare early childhood educators for this task. As more and more research demonstrates that content knowledge is a necessary, albeit insufficient, prerequisite for effective instruction, the minimal educational requirements for early childhood educators may become more similar to the requirements that govern $\mathrm{K}-12$ teachers.

In the past several years, the importance of providing all preschoolers with the opportunity to develop and actively practice emergent literacy skills has been demonstrated in many empirical studies (Lonigan, Burgess, \& Anthony, 2000; Whitehurst \& Fischel, 2000; Whitehurst \& Lonigan, 2001). This need is even more urgent in disadvantaged communities, where families are often unable to provide a high level of home-based literacy support, and preschools often lack resources. In fact, it has been demonstrated that when intervention programs focus on providing parents with strategies to develop language and literacy skills, students are more likely to experience both immediate and long-term reading gains (Sénéchal \& LeFevre, 2002; Whitehurst, Epstein, Angell, Payne, Crone, \& Fischel, 1994). Embedding emergent literacy instruction into preschool programs, particularly in disadvantaged communities, is a critical dimension of preparing students for elementary school (Dickinson \& Smith, 1994; Downer \& Pianta, 2006). Early literacy intervention programs implemented in high-poverty areas attempt to mediate the Matthew Effect (i.e., the rich get richer and the poor get poorer) as students who enter school without foundational literacy skills become increasingly unable to benefit from instruction over time (Stanovich, 1986; Walberg \& Tsai, 1983). It is often not acknowledged, though, that the degree to which such intervention programs are effective depends upon the quality of information presented, the style in which it is presented, and the readiness of the preschool teachers who deliver it.

\section{Operationalizing and measuring preschool teacher knowledge}

Fostering the development of such emergent literacy skills necessitates particular content knowledge and instructional practices, and thus, initiatives investigating the effectiveness of preschool literacy interventions have also grown in the past decade (e.g., Early Reading First, 2008). Even as intervention programs that target 
disadvantaged communities grow in scope and size, there is little evidence that such programs have increased teacher knowledge or shifted teacher practices in the long term. For such programs to be effective, researchers must specify what knowledge preschool teachers need to acquire, how researchers can reliably measure this acquired knowledge, and which instructional practices are most effective in teacher education in the domain of literacy. Little theoretical or practical attention has been paid to how researchers can begin to develop and deepen teacher knowledge within the domain of early literacy, yet research focusing on teacher knowledge and professional development in implementing a preschool curriculum is critical to the success of such programs. It is notable that, as standards for preschool learning become progressively more sophisticated and curricula are developed in conjunction with such standards, converging research continues to demonstrate that many early childhood educators are not prepared to instruct students in the domains of language and literacy (Early et al., 2006; Pianta et al., 2005). Until sufficient attention is dedicated to understanding the content and methods of professional development programs that help teachers acquire the requisite knowledge, these standards and supporting curricula have limited utility.

Foorman and Moats (2004) argued that "an empirical base is lacking for how to prepare teachers to teach reading" (p. 53). This is especially true in preschool. It is critical that preschool professional development opportunities are infused with what is known about the needs of beginning readers, especially those in low-performing, high-poverty schools. There is legitimate criticism of the current state of early childhood professional development. Although the relationship between high quality early childhood experiences and cognitive, social, and emotional development in children is well understood, professional development for preschool teachers "rarely focus[es] on curriculum, assessment, or a pre-school role in kindergarten readiness" (Freeman \& King, 2003, p. 77). Clearly, such a focus is long overdue.

\section{A study of preschool teacher knowledge}

In a recent study, we investigated preschool teachers' knowledge as part of a larger national study (Preschool Curriculum Evaluation Research Consortium, 2008), which focused on assessing the efficacy of many preschool language and mathematics curricula. Over the course of one school year, the 20 preschool teachers in this sample, all teaching in a high-poverty, urban setting, met monthly as a professional community of learners (Buysse, Sparkman, \& Wesley, 2003; Lewis, Perry, \& Murata, 2006; Pugach, 1999; Schmoker, 2007) in the form of a TSG to engage in discussions and skill-building around the topic of phonological awareness. In addition to the TSG, these teachers received feedback following classroom observations of their literacy practices, and mentoring over the course of the school year, from literacy leaders who facilitated the monthly discussions. Almost all of the teachers in this sample were older than 30 , credentialed, college graduates with prior teaching experience. More than half of these teachers had been teaching for at least 4 years prior to inclusion in the TSG. 


\section{The teacher knowledge assessment survey}

In both fall and spring of the school year, a measure of actual and perceived knowledge was administered to these teachers during TSG sessions. The teacher knowledge assessment survey (TKAS) assessed teachers' actual knowledge of spoken and written language structures, as well as their perceived knowledge of these structures and relevant instructional practices (see the appendix for TKAS questions). Many of the actual knowledge questions on this instrument were generated by revising Moats' (1994) measure discussed earlier in this paper. Thus, the TKAS investigates actual knowledge of phonology, word recognition, morphology, and orthography that Moats' elementary school teachers struggled with over a decade ago. Global perceived knowledge was assessed by asking teachers to predict how many of the 78 actual knowledge questions they answered accurately. Perceived knowledge was assessed with more specificity by examining teachers' responses to 11 questions regarding their knowledge of specific practices (e.g., "How would you describe your level of knowledge using assessment data to inform literacy instruction? A. Minimal, B. Moderate, C. Very Good, D. Expert”).

\section{Teacher knowledge gain}

Concurrently, measures of emergent language and literacy skills were administered to students. After analyzing the data collected during this intervention program, we found that even for those teachers whose scores on the measure of content knowledge were higher by program end, increases in teacher knowledge over the year had minimal effects on student gains. Many teachers' scores did not differ significantly from fall to spring. We had clearly overestimated the knowledge base and potential for knowledge gain of our preschool teacher sample.

Scores from spring testing, after teachers had participated in the TSG, indicated that more than half of the teachers sampled were only able to accurately respond to zero or one of the seven questions that required them to identify the number of speech sounds in words (e.g., sun, grass). Similarly, more than half of the teachers were only able to accurately respond to three or fewer of the seven questions that required them to identify the number of phonemes in words (e.g., bat, chalk). Phonics tasks, such as identifying regular and irregular verbs as well as consonant blends and digraphs, were also difficult for most teachers. Phoneme manipulation tasks were comparatively easier for teachers in this sample, as half of the sample correctly answered six or more of the nine questions that required them to reverse the phonemes in a word (e.g., the word checks becomes the word sketch). Additionally, it is notable that despite struggling to accurately respond to many of these questions, the preschool teachers in our sample overestimated their knowledge of these crucial skills. Teachers were asked to predict how many of the 78 questions on the TKAS they answered correctly. The mean estimate of correct answers as predicted by teachers $(M=51.94, S D=16.9)$ exceeded the actual mean score on the instrument $(M=40.8, S D=10.7)$.

In the course of analyzing the data gathered throughout this project (Cunningham, Davidson, \& Zibulsky, 2007), it became clear that both policymakers and 
researchers have unrealistically high expectations of the current instructional capabilities of early childhood educators, and that measurement tools used to assess whether these educators are approaching such expectations need to be developed. More work must be conducted to determine what professional development efforts empower preschool teachers and support students' language and literacy development. In order to understand the factors that make a professional development program effective, it is necessary to determine not only the content knowledge that must be provided during the program, but also the value that participants place on the acquisition of such knowledge, as well as the most effective ways to convey that knowledge. Measuring actual teacher knowledge, as well as teachers' perceptions of their own knowledge and beliefs regarding whether this knowledge will help them instruct students more effectively, are first steps in examining these factors. Although it is beyond the scope of this paper to discuss teacher beliefs concerning how to teach reading, it is important to note the reciprocal relationship between beliefs and knowledge. Teachers may choose not to engage in professional development around topics that they do not believe to be important, yet such beliefs are dependent upon their prior knowledge of research in this field. Future studies should include measures of actual knowledge, perceived knowledge, knowledge calibration, and teacher beliefs in order to more comprehensively assess factors that influence teacher receptiveness to participate in professional development. In this examination, we limit ourselves to exploring the first three of these four factors.

\section{Knowledge calibration: an important factor to consider}

In investigations of teacher knowledge factors in elementary educators, researchers have found that teachers lack knowledge not only of beginning literacy concepts, such as basic dimensions of phonological awareness, but also that their perceptions of their abilities are not well calibrated. For example, Cunningham et al. (2004) stated that "teachers tend to overestimate their reading related subject matter knowledge, and are often unaware of what they know and do not know" (p. 140). This finding is important for the field of teacher professional development because researchers from varied disciplines in education and psychology theorize that as learners (and specifically, adult learners) we are motivated to learn when (a) we think that a topic is relevant to our daily life (Knowles, 1980; Ryan \& Deci, 2000) and (b) we can accurately assess our lack of knowledge of that topic (Cunningham et al., 2004). Thus, recognizing the power of teacher beliefs in determining the type and amount of classroom learning is a necessary component in the creation of effective professional development opportunities.

Why knowledge calibration is important to consider for professional development

Although knowledge calibration has traditionally been examined within the critical thinking literature, it is useful to examine this construct within the domain of literacy and professional development. Reviews of previous research on knowledge calibration among teachers suggest that: 
People learn information more readily when they are relatively well calibrated as to their current level of knowledge because they can focus on areas where their knowledge is uncertain ... if teachers of beginning reading are well calibrated in their disciplinary knowledge, they presumably will be more receptive to seeking out and/or receiving information they do not possess. (Cunningham et al., 2004, pp. 143-144)

Therefore, teachers who are aware that they lack knowledge in one of these key literacy domains, such as phonological awareness, will likely be attentive to professional development about this topic. Conversely, teachers who cannot identify their own areas of weakness may not be receptive to new strategies, practices, and knowledge because they do not realize that they need this training. For this reason, measures of knowledge calibration include questions that ask teachers to assess their own knowledge in the domain of literacy, but only after asking them numerous questions that test their actual knowledge in this same domain (Cunningham et al., 2004, 2007). Researchers have ordered the tasks in this way on the assumption that because teachers have just engaged in tasks that challenged their phonological and phonics knowledge, they should be primed to assess their own abilities with the most accuracy possible.

Such reflection is a necessary component of teaching practice; it is only through actively knowing what one does not know that teachers can seek resources and training opportunities to ameliorate such deficits. Teachers who are not able to accurately assess their own knowledge need guidance in order to appraise their skills more realistically. Sharing measures of teacher knowledge with teachers, and consulting with them about their scores and progress on such measures, is essential to help them become well-calibrated and increase their knowledge. Because motivation plays a large role in teacher engagement in professional development programs, it stands to reason that knowledge calibration may moderate the effectiveness of professional development.

In this growing field, recent research does demonstrate that professional development plays a role in shifting teacher beliefs about the importance of specific content knowledge and particular instructional practices. Bos et al. (1999) found that, through professional development, early elementary school teachers gained a more positive regard toward the use of explicit reading instruction. As reported in this Special Issue, Brady et al. (in press) found that a significant amount of the variance associated with gains in teacher knowledge throughout a professional development program could be attributed to affective differences at the teacher level, such as whether teachers enrolled in the program primarily out of intrinsic interest or to earn continuing education units, and whether they felt that their school district was supportive of their attendance at the training. Including measures of knowledge calibration in future work of this nature may help identify additional variance in teacher knowledge gains.

Measuring knowledge calibration

In our previous work examining preschool teacher content knowledge and beliefs (Cunningham et al., 2007), three dimensions of knowledge were examined: literacy 
content knowledge, perceived content knowledge, and the ability to calibrate one's own knowledge level (the relationship between perceived and actual knowledge). Using instruments designed to test teacher knowledge and perceptions of knowledge, we sought to explore how actual and perceived knowledge (as well as the relationship between these two factors) affected teacher and student performance.

Actual knowledge questions on the TKAS required teachers to identify the numbers of sounds, syllables, and phonemes in words; to manipulate phonemes; and to identify regular and irregular words, as well as consonant blends and digraphs. The TKAS also included questions assessing teachers' perceptions of their actual knowledge by asking them to rate their knowledge in 11 areas of literacy and pedagogy (e.g. teaching literature, using assessment data, meeting the educational needs of diverse learners) on a Likert scale. Based on their responses to these 11 questions, their perceived knowledge was assessed at a global level.

Responses to four of these perceived knowledge questions, which were closely related to the actual knowledge tested on this measure, were examined at both item and composite levels. These items asked teachers to rate their own level of phonological awareness, their ability to teach children to become phonologically aware, their knowledge of phonics and the alphabetic principle, and their ability to teach children to understand phonics and the alphabetic principle. Phonological awareness and phonics are both domains of knowledge that are essential for reading acquisition (Dickinson \& Tabors, 2001) and have been definitively operationalized in the reading literature. Studies have shown that few elementary school teachers possess high levels of knowledge in these domains (Bos et al., 2001; Cunningham et al., 2004; Moats, 1994, 1995). It is particularly important to study knowledge calibration in these domains because determining whether teachers are aware of what they do and do not know may provide information regarding their attention to, and processing of, professional development activities that are critically important in supporting children's reading development. Because preschool teachers are likely to exhibit even less domain knowledge in these areas than elementary school teachers, the notion of knowledge calibration may be more essential to examine in this population to ensure active engagement in professional development opportunities.

In our study of preschool teachers over the course of a school year, it was observed that during both fall and spring testing, there was no evidence that teachers were well-calibrated in their knowledge. That is, no statistically significant relationships were found between actual and perceived knowledge. However, it is notable that by spring, more teachers were well-calibrated and fewer teachers overestimated their knowledge. Although these findings are nonsignificant, observing such a trend in a small sample is promising. This trend may indicate that the type of deep discussions generated about phonological awareness in TSG sessions help teachers begin to calibrate their own knowledge. Teachers who possess little knowledge in particular domains may need to recognize their skill deficits before beginning to benefit from professional development. However, further research must be conducted to identify the saturation point of such professional development efforts.

Although strong effects on the composite measure of teacher knowledge were not observed, we hypothesized that relationships might exist at the subscale level. 
Analyses were conducted to examine the relationships between the four previously mentioned questions that measured teachers' perceived knowledge of their own phonological awareness, their own ability to teach children to become phonologically aware, their own phonics knowledge, and their ability to teach children sound/ symbol correspondence and actual knowledge subscales on the TKAS that focused on phonological and phonics knowledge. A relatively strong positive relationship $(r=.62, p<.005)$ was found between perceived ability to teach children to become phonemically aware, and teachers' actual level of phonological awareness (operationalized as the ability to identify the number of phonemes in words). At this one specific level, perceived and actual knowledge appear to be directly associated.

\section{Approaching knowledge calibration}

It is notable that in the domain of phonological awareness, the actual knowledge of preschool teachers was associated with their belief that they could instruct students in the development of a particular skill. This finding indicates that many preschool teachers may be in the process of developing their own domain knowledge of phonological awareness. More than half of the preschool teachers surveyed had difficulty identifying the number of phonemes in words. Yet these teachers were also relatively aware of their difficulties in this area, and thus likely to state that they would have difficulty imparting this skill to children. In contrast, these teachers had just as much-if not more-difficulty on other sections of the TKAS, yet did not seem as aware of their difficulties in these areas. It can then be said with some confidence, both theoretically and empirically, that helping preschool teachers develop phonological awareness skills may be the most logical starting place for a professional development intervention. Furthermore, tests of teacher knowledge should be developed that can elucidate the range of knowledge that these teachers possess. In this Special Issue, Carlisle, Correnti, Phelps, and Zeng (in press) call for instruments that not only have strong internal reliability, but that are tied to pedagogical content knowledge or application in the classroom. With teachers of very young children, we must develop and administer instruments that test their knowledge of the language and literacy skills that are immediately applicable in their classrooms.

On an instrument such as the TKAS, which traditionally assesses knowledge of elementary school teachers, results with preschool teachers are likely to show a "floor" effect. Moats' (1994) original measure of teacher knowledge in the domain of literacy, which has been revised by our research group along with many others, was originally designed to measure the knowledge of elementary school teachers. More research exists that can be used to document the differences between the knowledge base of elementary and preschool teachers than that which can be used to highlight within-group differences, particularly those of preschool teachers. Based on the research that we have conducted with preschool teachers over the past few years, evidence suggests that a scaled down version of this instrument that focuses only and comprehensively on measuring phonological awareness and alphabetic principle skills would provide a richer and more applicable measure of the knowledge base of preschool teachers. 
Calibration as a precursor to knowledge gain

Implementing programs that help teachers accurately assess their own knowledge is perhaps a prerequisite to gaining actual knowledge through professional development. It is only when teachers realize they need support that they will internalize the instructional practices and strategies suggested in professional development programs, even in supportive settings such as teacher study groups. If preschool teachers were to appear unreceptive to professional development or overly confident of their domain knowledge, it might be important to assess their knowledge and provide graduated interventions that more effectively address their needs. One important step to take in this endeavor would be to develop intervention components that directly address poor knowledge calibration. This strategy would require more frequent assessments of teacher knowledge, through both formal and informal means. Furthermore, the results of these assessments would need to be shared with teachers in such a way that educated them about their own skill and knowledge deficits without decreasing their motivation and enthusiasm for the program. Finally, knowledge and skill deficits would need to be explicitly addressed during the meetings of the professional community of learners, which necessitates flexibility on the part of the coordinator so that teachers' needs can be met as they arise.

To accomplish some of these goals, teacher professional development programs may consider embracing the model that is being applied to the students they teach. The Response to Intervention (RTI) model currently being implemented in public schools attempts to prevent and remediate learning problems though strong, universal curricular supports and the provision of additional instruction to struggling students. The RTI model delineates successive tiers of treatment, each increasingly intensive, to help all learners develop foundational skills. "Rather than relying on static test-based measures or a student's response to single interventions, RTI decision making is based upon direct assessments of students' response to varying levels of intervention intensity" (Ardoin, Witt, Connell, \& Koenig, 2005, p. 362). RTI may be a useful way to frame professional development efforts for teachers as well; all teachers could receive basic support in learning to effectively teach early language and literacy skills (e.g., enroll in a professional development program), and only treatment resistant teachers - those who have low actual knowledge or are inaccurate in their perceptions of their own knowledge-would progress to the next tier of professional development. Although implementing such a system would make professional development efforts less standardized and thus more timeconsuming to implement, it is important to recognize that teachers are just as likely as students to have individual needs, areas of strength and weakness, and varying responses to different types of instruction. Such changes to the prevailing model of professional development may be perceived as radical, but this point is likely obvious to many researchers who have implemented similar interventions, as Moats' (in press) article in this Special Issue attests. It is clear that one-size-fits-all interventions, for many teachers, do not affect actual or perceived knowledge.

In summary, our research indicates that instruments that allow researchers to characterize the range of knowledge that these preschool teachers possess still need 
to be developed, and that many early childhood educators do not accurately identify their own knowledge of literacy and pedagogy. Creating professional development programs that focus on priming teachers to be receptive to knowledge (through knowledge calibration) is an important step for the field to take for both early elementary school teachers and early childhood educators. As such programs are developed, it is essential to clearly operationalize the knowledge teachers should have and to develop valid and reliable measures that can assess actual and perceived knowledge.

Being a skilled reader is not a sufficient condition for being a skilled reading teacher. Although this fact is becoming more broadly understood, and the practices of and policies regarding elementary school educators reflect this increased understanding, considerably less attention has been devoted to supporting early childhood educators in acquiring the disciplinary knowledge needed to support their younger students' emergent literacy development. This job, too, is one for an expert. The reading research community will demonstrate its commitment to early childhood educators by crafting professional development programs that are compelling and that help educators calibrate and acquire content knowledge.

Acknowledgements Special thanks to the teachers, students, and facilitators who made this study possible. Portions of these data were presented at the Biennial Meeting of the Society for Research in Child Development, Boston, MA, 2007. The UC Berkeley Preschool Curriculum Evaluation Research project was supported by the U.S. Department of Education, Institute for Educational Sciences under Grant \# R305M05037.

Open Access This article is distributed under the terms of the Creative Commons Attribution Noncommercial License which permits any noncommercial use, distribution, and reproduction in any medium, provided the original author(s) and source are credited.

\section{Appendix}

\section{Teacher Knowledge Assessment Survey (TKAS)}

This is a questionnaire designed to assess your present knowledge of aspects of oral and written language. Please carefully read the directions for each section and mark the answer(s) you feel are most appropriate.

Thank you in advance for your thorough and professional response to our research survey.

Does the word scratch contain a consonant blend? a. Yes b. No

If $e$ were the only vowel in an open syllable, the $e$ would most likely represent the same sound as:
a. The $e$ in pine
b. The ea in meat
c. The $y$ in $m y$
d. The $e$ in set
e. None of these 
Count the number of simple speech sounds you hear in each of the words below and circle the correct answer to the right of the word. Do this for each of the words listed.

Example: Cat has three sounds: /c/ /a/ /t/

$\begin{array}{llllll}\text { grass } & \text { a. one sound } & \text { b. two } & \text { c. three } & \text { d. four } & \text { e. five } \\ \text { say } & \text { a. one sound } & \text { b. two } & \text { c. three } & \text { d. four } & \text { e. five }\end{array}$

Say each of the following words out loud. Then reverse the order of the sounds, and say the new English word that results. Write the new word with its conventional (correct) English spelling on the line to the right of the word. Do this for each of the words.

Example: The word age becomes the word jay.

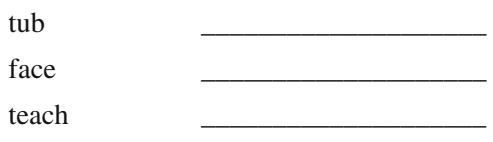

All of the following are common words that children are usually taught to read in first grade. Some of these words are phonetically regular (i.e., they conform to frequently taught phonic rules in English and can be sounded out), whereas others are phonetically irregular (i.e., they are exceptions to phonic rules). Please indicate whether each of the words is phonetically regular or irregular.
the
a. Regular
b. Irregular
done
a. Regular
b. Irregular
tea
a. Regular
b. Irregular

For each of the words shown below, count the syllables and circle the correct number of syllables to the right of the word.

Example: The word elephant has 3 syllables: /el/ /e/ /phant/
unbelievable
a. three
b. four
c. five
d. six
e. seven
finger
a. one
b. two
c. three
d. four
e. five
hopeful
a. one
b. two
c. three
d. four
e. five

Read the first word in each line, and note the sound that is represented by the underlined letter or letters. Then circle the word to the right that contains the same sound.
paper
a. village
b. father
c. pal
d. sleigh
rose
a. dazzle
b. rust
c. assign
d. tissue
push
a. just
b. jump
c. should
d. soup

Count the number of phonemes you hear in each of the words below. A phoneme is the smallest unit of sound; it is smaller than a syllable.

Example: The word meat has three phonemes: /m/ /e/ /t/

$\begin{array}{llllll}\text { bat } & \text { a. one sound } & \text { b. two } & \text { c. three } & \text { d. four } & \text { e. five } \\ \text { though } & \text { a. one sound } & \text { b. two } & \text { c. three } & \text { d. four } & \text { e. five } \\ \text { weight } & \text { a. one sound } & \text { b. two } & \text { c. three } & \text { d. four } & \text { e. five }\end{array}$




\section{Regarding the type of knowledge contained in the previous questions, please answer the following:}

How important do you think it is for preschool teachers to understand this type of knowledge?
a. Very important
b. Somewhat important
c. Not very important
d. Not important at all

How well do you think you did on the questions above?
a. Very well
b. Fairly well
c. Not very well
d. Poorly

Of the first 78 questions we asked you, how many items do you estimate or think you answered correctly? Please respond on the blank line below.

178

Of all of the preschool teachers completing this survey, please indicate how well you think you did compared to the others.
a. Well below average
b. A little below average
c. A little above average
d. Well above average

\section{References}

Ackerman, D. J. (2004). States' efforts in improving the qualifications of early care and education teachers. Educational Policy, 18, 311-337. doi:10.1177/0895904803262145.

Adams, M. (1990). Beginning to read: Thinking and learning about print. Cambridge, MA: Massachusetts Institute of Technology.

Ardoin, S. P., Witt, J. C., Connell, J. E., \& Koenig, J. L. (2005). Application of a three-tiered response to intervention model for instructional planning, decision making, and the identification of children in need of services. Journal of Psychoeducational Assessment, 23, 362-380. doi:10.1177/0734282 90502300405 .

Arnold, R. (2005). Charming the next generation: Strategies for turning toddlers into readers. School Library Journal, 51, 30-32.

Blachman, B. A., Schatschneider, C., Fletcher, J. M., Francis, D. J., Clonan, S. M., Shaywitz, B. A., et al. (2004). Effects of intensive reading remediation for second and third graders and a 1-year follow-up. Journal of Educational Psychology, 96, 444-461. doi:10.1037/0022-0663.96.3.444.

Bos, C., Mather, N., Dickson, S., Podhajski, B., \& Chard, D. (2001). Perceptions and knowledge of preservice and inservice educators about early reading instruction. Annals of Dyslexia, 51, 97-120. doi:10.1007/s11881-001-0007-0.

Bos, C. S., Mather, N., Narr, R. F., \& Babur, N. (1999). Interactive, collaborative professional development in early literacy instruction: Supporting the balancing act. Learning Disabilities Research \& Practice, 14, 227-238. doi:10.1207/sldrp1404_4. 
Brady, S., Gillis, M., Smith, T., Lavalette, M., Liss-Bronstein, L., Lowe, E., et al. (in press). First grade teachers' knowledge of phonological awareness and code concepts: Examining gains from an intensive form of professional development. Reading and Writing: An Interdisciplinary Journal.

Brady, S., \& Moats, L. (1997). Informed instruction for reading success: Foundations to teacher preparation. Baltimore: International Dyslexia Association.

Burchinal, M., Hyson, M., \& Zaslow, M. (June, 2008). Competencies and credentials for early childhood educators: What do we know and what do we need to know? Presentation at Head Start's Ninth National Research Conference, Washington, DC.

Buysse, V., Sparkman, K. L., \& Wesley, P. W. (2003). Communities of practice: Connecting what we know with what we do. Exceptional Children, 69, 263-277.

California Department of Education. (2008). California preschool learning foundations (Vol. 1). Retrieved March 28, 2008, from http://www.cde.ca.gov/re/pn/fd/documents/preschoollf.pdf.

Carlisle, J. F., Correnti, R., Phelps, G., \& Zeng, J. (in press). Exploration of the contribution of teachers' knowledge about reading to their students' improvement in reading. Reading and Writing: An Interdisciplinary Journal.

Cirino, P. T., Pollard-Durodola, S. D., Foorman, B. R., Carlson, C. D., \& Francis, D. J. (2007). Teacher characteristics, classroom instruction, and student literacy and language outcomes in bilingual kindergartners. The Elementary School Journal, 107, 341-364.

Clark, C. M., \& Peterson, P. L. (1986). Teachers' thought processes. In M. C. Wittrock (Ed.), Handbook of research on teaching (3rd ed., pp. 255-296). New York: Macmillan.

Clingenpeel, B. T., \& Pianta, R. C. (2007). Mothers' sensitivity and book-reading interactions with first graders. Early Education and Development, 18, 1-22.

Constantino, R. (2005). Print environments between high and low socioeconomic status communities. Teacher Librarian, 32, 22-25.

Cunningham, A. E. (1990). Explicit versus implicit instruction in phonemic awareness. Journal of Experimental Child Psychology, 50, 429-444.

Cunningham, A. E., \& Davidson, M. (2005, June). Current models of professional development for reading education: Teacher study groups. Invited paper presented at the Pacific Resources for Education and Learning (PREL), Honolulu, HI.

Cunningham, A. E., Davidson, M., \& Zibulsky, J. (2007, March). Teacher study groups as a mechanism of change in professional development in preschool literacy curricula: Developing teacher knowledge. Paper presented at the Bi-Annual Meeting of the Society for Research in Child Development, Boston, MA.

Cunningham, A. E., Perry, K. E., Stanovich, K. E., \& Stanovich, P. J. (2004). Disciplinary knowledge of K-3 teachers and their knowledge calibration in the domain of early literacy. Annals of Dyslexia, 54, 139-172.

Cunningham, A. E., \& Stanovich, K. E. (1997). Early reading acquisition and its relation to reading experience and ability ten years later. Developmental Psychology, 33, 934-945.

Davidson, M., \& Cunningham, A. E. (2005, August). Teacher lesson study groups: A collaborative framework for professional development. Paper presented at the Maine Early Reading First Conference, Belfast, ME.

Dickinson, D. K. (2002). Shifting images of developmentally appropriate practice as seen through different lenses. Educational Researcher, 31(1), 26-32.

Dickinson, D. K., \& Brady, J. P. (2006). Toward effective support for language and literacy through professional development. In M. Zaslow \& I. Martinez-Beck (Eds.), Critical issues in early childhood professional development (pp. 141-170). Baltimore: Paul H. Brookes Publishing Co. Inc.

Dickinson, D. K., \& McCabe, A. (2001). Bringing it all together: The multiple origins, skills and environmental supports of early literacy. Learning Disabilities Research and Practice, 16, 186-202.

Dickinson, D. K., \& Smith, M. W. (1994). Long-term effects of preschool teachers' book readings on lowincome children's vocabulary and story comprehension. Reading Research Quarterly, 29, 104-122.

Dickinson, D. K., \& Tabors, P. O. (Eds.). (2001). Building literacy with language: Young children learning at home and school. Baltimore: Brookes.

Downer, J., \& Pianta, R. (2006). Academic and cognitive functioning in first grade: Associations with earlier home and child care predictors and with concurrent home and classroom experiences. School Psychology Review, 35, 11-30.

Duke, N. K. (2000). For the rich it's richer: Print experiences and environments offered to children in very low- and very high-socioeconomic status first-grade classrooms. American Educational Research Journal, 37, 441-478. 
Duncan, G., \& Brooks-Gunn, J. (Eds.). (1997). Consequences of growing up poor. New York: Russell Sage Foundation.

Early, D. M., Bryant, D., Pianta, R., Clifford, R., Burchinal, M., Ritchie, S., et al. (2006). Are teacher education, major, and credentials related to classroom quality and children's academic gains in prekindergarten? Early Childhood Research Quarterly, 21, 174-195.

Early Reading First. (2008). Early reading first: Purpose. Retrieved May 28, 2008, from http://www.ed.gov/programs/earlyreading/index.html.

Foorman, B. R., \& Moats, L. C. (2004). Conditions for sustaining research-based practices in early reading instruction. Remedial \& Special Education, 25, 51-60.

Foorman, B. R., \& Torgesen, J. (2001). Critical elements of classroom and small-group instruction promote reading success in all children. Learning Disabilities Research \& Practice: Special Issue: Emergent and Early Literacy: Current Status and Research Directions, 16, 203-212.

Freeman, G. D., \& King, J. L. (2003). A partnership for school readiness. Educational Leadership, 60, 76-79.

Gage, N. (1978). The scientific basis of the art of teaching. New York: Teachers College Press.

Greene, J. F. (1998). Another chance: Help for older students with limited literacy. American Educator, Spring/Summer, 74-79.

Grossman, P. L., Wilson, S. M., \& Shulman, L. S. (1989). Teachers of substance: Subject matter knowledge for teaching. In M. C. Reynolds (Ed.), Knowledge base for the beginning teacher (pp. 23-36). New York: Pergamon.

Hart, B., \& Risley, T. R. (1992). American parenting of language-learning children: Persisting differences in family-child interactions observed in natural home environments. Developmental Psychology, 28, 1096-1106.

Hill, H. C., Rowan, B., \& Ball, D. L. (2005). Effects of teachers' mathematical knowledge for teaching on student achievement. American Educational Research Journal, 42, 371-406.

Juel, C. (2006). The impact of early school experiences on initial reading. In D. K. Dickinson \& S. B. Neuman (Eds.), Handbook of early literacy research (Vol. 2, pp. 410-444). New York: Guilford Press.

Knowles, M. S. (1980). The modern practice of adult education from pedagogy to andragogy. Englewood Cliffs, NJ: Cambridge Adult Education.

Lampert, M. (1988). What can research on teacher education tell us about improving quality in mathematics education? Teaching and Teacher Education, 4, 157-170.

Lash, M., McMullen, M. B., \& Alat, K. (2003, April). Should a four-year degree be required for preschool teachers? Presentation at the American Education Research Association, Chicago, IL.

Lewis, C., Perry, R., \& Murata, A. (2006). How should research contribute to instructional improvement? The case of lesson study. Educational Researcher, 35, 3-14.

Lonigan, C. J., Burgess, S. R., \& Anthony, J. L. (2000). Development of emergent literacy and early reading skills in preschool children: Evidence from a latent-variable longitudinal study. Developmental Psychology, 36, 596-613.

Lyon, G. R. (1998). Overview of reading and literacy initiatives. CORE Reading Research Anthology. Novato, CA: Arena Press.

Lyon, G. R., Vaassen, M., \& Toomey, F. (1989). Teacher perceptions of their undergraduate and graduate training. Teacher Education and Special Education, 12, 164-169.

McCutchen, D., Abbott, R. D., Green, L. B., Beretvas, S. N., Cox, S., Potter, N. S., et al. (2002). Beginning literacy: Links among teacher knowledge, teacher practice, and student learning. Journal of Learning Disabilities, 35, 69-86.

McCutchen, D., \& Berninger, V. W. (1999). Those who know, teach well: Helping teachers master literacy-related subject-matter knowledge. Learning Disabilities Research \& Practice, 14, 215-226.

McCutchen, D., Green, L., \& Abbott, R. D. (in press). Further evidence for teacher knowledge: Supporting struggling readers in grades three through five. Reading and Writing: An Interdisciplinary Journal.

McCutchen, D., Harry, D. R., Cunningham, A. E., Cox, S., Sidman, S., \& Covill, A. E. (2002). Reading teachers' knowledge of children's literature and English phonology. Annals of Dyslexia, 52, 207-228.

Moats, L. C. (1994). The missing foundation in teacher education: Knowledge of the structure of spoken and written language. Annals of Dyslexia, 44, 81-104.

Moats, L. C. (1995). The missing foundation in teacher education. American Federation of Teachers, 44, 81-102. 
Moats, L. C. (1999). Teaching reading is rocket science: What expert teachers of reading should know and be able to do. Washington, DC: American Federation of Teachers.

Moats, L. C. (in press). Knowledge foundations for teaching reading and spelling. Reading and Writing: An Interdisciplinary Journal.

National Reading Panel. (2000). Teaching children to read: An evidence-based assessment of the scientific research literature on reading and its implications for reading instruction. Washington, DC: National Institute of Child Health and Human Development.

National Research Council. (1999). Starting out right: A guide to promoting children's reading success. Washington, DC: National Academy Press.

Needlman, R., Toker, K. H., Dreyer, B. P., Klass, P., \& Mendelsohn, A. L. (2005). Effectiveness of a primary care intervention to support reading aloud: A multicenter evaluation. Ambulatory Pediatrics, 5, 209-215.

Neuman, S. B., \& Celano, D. (2001). Access to print in middle- and low-income communities: An ecological study of four neighborhoods. Reading Research Quarterly, 36, 8-26.

Nolan, P. A., McCutchen, D., \& Berninger, V. (1990). Ensuring tomorrow's literacy: A shared responsibility. Journal of Teacher Education, 41, 63-72.

O'Connor, R. (1999). Teachers learning ladders to literacy. Learning Disabilities Research \& Practice, 14, 203-214.

Oudeans, M. K. (2003). Integration of letter-sound correspondences and phonological awareness skills of blending and segmenting: A pilot study examining the effects of instructional sequence on word reading for kindergarten children with low phonological awareness. Learning Disability Quarterly, 26, 258-280.

Phelps, G., \& Schilling, S. (2004). Developing measures of content knowledge for teaching reading. Elementary School Journal, 105, 31-48.

Pianta, R., Howes, C., Burchinal, M., Bryant, D., Clifford, R., Early, D., et al. (2005). Features of prekindergarten programs, classrooms, and teachers: Do they predict observed classroom quality and child-teacher interactions? Applied Developmental Science, 9, 144-159.

Preschool Curriculum Evaluation Research Consortium. (2008). Effects of preschool curriculum programs on school readiness: Preschool curriculum evaluation research multi-program evaluation report. Washington, DC: National Center for Educational Statistics, Institute of Educational Sciences.

Princiotta, D., Flanagan, K., \& Germino Hausken, E. (2006). Fifth grade: Findings from the fifth-grade follow-up of the early childhood longitudinal study, kindergarten class of 1998-99 (NCES 2006038). Washington, DC: National Center for Educational Statistics.

Pugach, M. C. (1999). The professional development of teachers from a "communities of practice" perspective. Teacher Education and Special Education, 22, 217-233.

Raver, C. C., \& Zigler, E. F. (2004). Public policy viewpoint. Another step back? Assessing readiness in Head Start. Young Children, 59, 58-63.

Rayner, K., Foorman, B., Perfetti, C., Pesetsky, D., \& Seidenberg, M. (2001). How psychological science informs the teaching of reading. Psychological Science in the Public Interest, 2, 31-74.

Roskos, K., Rosemary, C. A., \& Varner, M. H. (2006). Alignment in educator preparation for early and beginning literacy instruction: A state-level case example. In M. Zaslow \& I. Martinez-Beck (Eds.), Critical issues in early childhood professional development (pp. 255-282). Baltimore: Paul H. Brookes Publishing Co. Inc.

Ryan, R. M., \& Deci, E. L. (2000). Self-determination theory and the facilitation of intrinsic motivation, social development, and well-being. American Psychologist, 55, 68-78.

Scarborough, H. S., Ehri, L. C., Olson, R. K., \& Fowler, A. E. (1998). The fate of phonemic awareness beyond the elementary school years. Scientific Studies of Reading, 2, 115-142.

Schmidt, K. (2008, March). Head Start teachers' pedagogical content knowledge of emergent literacy. Poster presented at the annual conference for the Graduate School of Education, University of California, Berkeley, CA.

Schmoker, M. J. (2007). Results now: How we can achieve unprecedented improvements in teaching and learning. Alexandria, VA: ASCD.

Sénéchal, M., \& LeFevre, J. (2002). Parental involvement in the development of Children's reading skill: A five-year longitudinal study. Child Development, 73, 445-460.

Snow, C. E., Griffin, P., \& Burns, M. S. (Eds.). (2005). Knowledge to support the teaching of reading. A model of professional growth in reading education (pp. 201-223). San Francisco: Jossey-Bass. 
Spear-Swerling, L., \& Brucker, P. O. (2004). Preparing novice teachers to develop basic reading and spelling skills in children. Annals of Dyslexia, 54, 332-364.

Spear-Swerling, L., \& Sternberg, R. J. (2001). What science offers teachers of reading. Learning Disabilities Research \& Practice, 16, 51-57.

Stanovich, K. E. (1986). Matthew effects in reading: Some consequences of individual difference in the acquisition of literacy. Reading Research Quarterly, 21, 360-407.

Thompson, A. G. (1992). Teachers' beliefs and conceptions: A synthesis of the research. In D. A. Grouws (Ed.), Handbook of research on mathematics teaching and learning (pp. 127-146). New York: Macmillan.

U.S. Department of Health and Human Services. (2003). President Bush's plan to prepare children for Kindergarten. Retrieved March 28, 2008, from http://www.hhs.gov/news/press/2003pres/2003 0203.html.

Walberg, H. J., \& Tsai, S. (1983). Matthew effects in the classroom. American Educational Research Journal, 20, 359-373.

Whitehurst, G. J., Epstein, J. N., Angell, A. L., Payne, A. C., Crone, D. A., \& Fischel, J. E. (1994). Outcomes of an emergent literacy intervention in head start. Journal of Educational Psychology, 86, 542-555.

Whitehurst, G. J., \& Fischel, J. E. (2000). A developmental model of reading and language impairments arising in conditions of economic poverty. In D. Bishop \& L. Leonard (Eds.), Speech and language impairments in children: Causes, characteristics, intervention and outcome (pp. 53-71). East Sussex, UK: Psychology Press.

Whitehurst, G. J., \& Lonigan, C. J. (2001). Emergent literacy: Development from prereaders to readers. In S. B. Neuman \& D. K. Dickinson (Eds.), Handbook of early literacy research (pp. 11-42). New York: Guilford Press.

Wilson, S., Shulman, L., \& Richert, A. (1987). "150 Different ways of knowing”: Representations of knowledge in teaching. In J. Calderhead (Ed.), Exploring teachers' thinking (pp. 104-123). Eastbourne, England: Cassell.

Wilson, S., \& Wineburg, S. (1988). Peering at history through different lenses: The role of disciplinary perspectives in teaching history. Teachers College Record, 89, 525-539.

Wong-Fillmore, L., \& Snow, C. E. (2002). What teachers need to know about language. In C. T. Adger, C. E. Snow, \& D. Christian (Eds.), What teachers need to know about language (pp. 7-54). McHenry, IL: Delta Systems Co., Inc. 